\title{
Factors affecting the severity of the apnea hypoapnea index: a retrospective study on 838 Egyptian patients diagnosed with obstructive sleep apnea
}

\author{
Ahmed Gharib ${ }^{1,2^{*}}$ (1) and Shahira Loza ${ }^{2}$
}

\begin{abstract}
Background: Obstructive sleep apnea (OSA) is a common condition in the general population that is highly correlated to obesity, and it is associated with major cardiovascular morbidity and mortality. In Egypt, obesity rates are known to be high; however, OSA remains largely under-diagnosed, and data on its current magnitude is very scarce. Thus, the aims of the study were to identify the percentage of OSA in a large sample of patients referred for polysomnography and to determine the effect of different demographic data on the severity of the disease.

Results: This retrospective study included 1012 patients. Medical data were reviewed by sleep specialists. The correlation between age, body mass index (BMI), and neck circumference (NC) with apnea hypoapnea index (AHI) was explored. Also, gender differences were analyzed. A total of 838 patients ( $81 \%$ males, $19 \%$ females) were diagnosed with OSA. Patients with mild, moderate, and severe OSA were 204 (24\%), 146 (17\%), and 488 (58\%), respectively. Females were older than males $(58.87 \pm 10.25$ versus $54.39 \pm 22.96, p=0.001)$ and BMI was not significantly different between both sexes (34.18 \pm 13.53 versus $36.73 \pm 23.25, p=0.07)$, but NC was higher in men $(43.56 \pm 5.3$ versus $39.34 \pm 4.41, p=0.001)$. AHI was significantly increased in men compared to women $(47.97 \pm$ 31.22 versus $37.95 \pm 31.72, p=0.001)$ and severe OSA was commonly diagnosed in men than women $(p=0.001)$. A positive significant correlation was found between $\mathrm{BMI}, \mathrm{NC}$ with $\mathrm{AHI}$, arousal index, average $\mathrm{SpO}_{2}$, and desaturation index.
\end{abstract}

Conclusion: OSA is highly prevalent among our patients. Additionally, BMI and NC independently affected the severity of their disease.

Keywords: OSA, Obesity, Neck circumference, Gender, AHI

\section{Background}

Obstructive sleep apnea (OSA) is a common and chronic condition characterized by episodes of complete or partial obstruction of the upper airway leading to intermittent hypoxia, frequent arousals, and daytime sleepiness [1]. Well-known risk factors that increase the risk of

\footnotetext{
*Correspondence: ahmedgharib@hotmail.com

'Pulmonary Research Unit, Department of Internal Medicine, National Research Center, Cairo, Egypt

${ }^{2}$ Cairo Center for Sleep Disorders, Cairo, Egypt
}

OSA include obesity, age, male gender, upper airway anatomical abnormalities, or hormonal influences [2].

The prevalence of OSA, even though still underdiagnosed, has been investigated in different Western population cohorts, varying around $34 \%$ for men and $17 \%$ for women [3]. This incidence of OSA is expected to rise even more with the explosion of the obesity epidemics around the world [4]. However, even with the high obesity rates known in the Egyptian population affecting $37.1 \%$ in men and $50.8 \%$ in women [5-7], data

\section{Springer Open}

(c) The Author(s). 2020 Open Access This article is licensed under a Creative Commons Attribution 4.0 International License, which permits use, sharing, adaptation, distribution and reproduction in any medium or format, as long as you give appropriate credit to the original author(s) and the source, provide a link to the Creative Commons licence, and indicate if changes were made. The images or other third party material in this article are included in the article's Creative Commons licence, unless indicated otherwise in a credit line to the material. If material is not included in the article's Creative Commons licence and your intended use is not permitted by statutory regulation or exceeds the permitted use, you will need to obtain permission directly from the copyright holder. To view a copy of this licence, visit http://creativecommons.org/licenses/by/4.0/. 
regarding the prevalence of OSA in Egypt is still very limited.

Also, OSA is a known risk factor for many comorbid disorders, causing resistance to conventional treatments and increasing the risk of mortality, which multiplies health care expenditures $[8,9]$, and even though the distribution of comorbidities differs between men and women, their effect progressively increases with OSA severity [10]. Furthermore, a Danish study concluded that male gender, age, and continuous positive airway pressure (CPAP) treatment were the predictor variables for quality of life and survival in patients with OSA [11].

In fact, studies have shown that age aggravates OSA in males and in postmenopausal females due to hormonal influences [2]. It was also observed that cardiovascular (CV) diseases were more pronounced after 60 years of age [12]. Evidence from epidemiological studies supports an association between OSA and CV diseases such as coronary heart disease, arrhythmia, heart failure, and stroke $[13,14]$.

In addition, strong associations have been reported between OSA and the prevalence of hypertension (HTN) independently of other CV risk factors [15]. Further, a recent cross-sectional study conducted on around 4000 Egyptian patients with HTN found that $63 \%$ of the cohort had uncontrolled blood pressure values despite treatment, and about half of those patients had an increased BMI [16].

To our knowledge, no previous studies evaluated the effect neither of obesity, gender, age, nor of the NC on the severity of OSA in a large number of Egyptian patients. Thus, considering the important health-related consequences notably the cardiovascular morbidity and mortality associated with OSA, we sought to evaluate the incidence of the disease and to determine the factors that might affect its severity among our patients. In this work, we also shed the light on the differences existing between males and females diagnosed with OSA.

\section{Methods}

This was a retrospective study on 1012 patients referred for evaluation of sleep-related breathing disorders at the Cairo Center for Sleep Disorders, an outpatient private center in Cairo, Egypt, between January 2012 and December 2014. This study was conducted in accordance with the International Committee of Harmonization Guidelines for Good Clinical Practice with applicable local regulations and ethical principles laid down in the Declaration of Helsinki. All medical files were reviewed by sleep specialists. Data collected included full medical history, demographics, measurements of weight and height, body mass index in kilograms per square meter, neck circumference (NC), Epworth Sleepiness Scale (ESS) scores, and the diagnosis that was concluded after
Table 1 Demographics and clinical characteristics of patients diagnosed with OSA

\begin{tabular}{|c|c|c|c|}
\hline & & Mean & $\pm S D$ \\
\hline \multicolumn{2}{|l|}{ Age (years) } & 55.25 & 21.20 \\
\hline \multicolumn{2}{|l|}{ Weight (kg) } & 111.83 & 43.68 \\
\hline \multicolumn{2}{|l|}{ Height (cm) } & 171.87 & 54.41 \\
\hline \multicolumn{2}{|l|}{ BMI $\left(\mathrm{kg} / \mathrm{m}^{2}\right)$} & 34.67 & 15.88 \\
\hline \multirow{2}{*}{\multicolumn{2}{|c|}{$\mathrm{NC}(\mathrm{cm})$}} & 42.78 & 5.40 \\
\hline & & Number & $\%$ \\
\hline \multirow[t]{2}{*}{ Sex } & Male & 678 & 81 \\
\hline & Female & 160 & 19 \\
\hline \multirow[t]{2}{*}{ Hypertension } & Yes & 344 & 41.1 \\
\hline & No & 494 & 58.9 \\
\hline
\end{tabular}

$B M I$ body mass index, $N C$ neck circumference

a polysomnography study. Laboratory full night diagnostic polysomnography that was attended by a sleep technician and performed using the Alice 5 or Alice 6 Diagnostic Sleep system (Philips Respironics Inc., Murrysville, PA, USA) involved the recording of electroencephalography with two frontal derivations, two central derivations, two occipital derivations, right and left eye derivations, nasal pressure, nasal-oral airflow (thermal device), snore sensor, respiratory effort (abdominal and thoracic effort), oxygen saturation with pulse oximetry, submental EMG, and right and left anterior tibialis EMG. Polysomnography results were scored and interpreted manually according to the American Academy of Sleep Medicine Manual for the scoring of sleep events defining apnea events as the cessation of airflow by $\geq$ $90 \%$ for at least $10 \mathrm{~s}$ and hypopnea events as a reduction in the airflow by $\geq 30 \%$ for at least $10 \mathrm{~s}$ and oxygen desaturation of $\geq 4 \%$ [17]. Patients included in the study

Table 2 Description of the sleep data of the patients diagnosed with OSA

\begin{tabular}{|c|c|c|c|c|c|}
\hline & & Mean & $\pm \mathrm{SD}$ & IQR & \\
\hline \multicolumn{2}{|l|}{ ESS } & 10.34 & 6.41 & 6.00 & 15.00 \\
\hline \multicolumn{2}{|l|}{ TST } & 301.52 & 91.14 & 246.00 & 365.50 \\
\hline \multicolumn{2}{|l|}{$\mathrm{Al}$} & 35.75 & 24.84 & 16.00 & 55.00 \\
\hline \multicolumn{2}{|l|}{$\mathrm{SpO}_{2}$} & 91.52 & 7.06 & 90.00 & 95.00 \\
\hline \multicolumn{2}{|l|}{$\mathrm{DI}$} & 55.94 & 43.24 & 18.70 & 84.50 \\
\hline \multirow{2}{*}{\multicolumn{2}{|c|}{$\mathrm{AHI}$}} & 46.05 & 31.54 & 15.50 & 73.50 \\
\hline & & Number & $\%$ & & \\
\hline \multirow[t]{3}{*}{ OSA } & Mild & 204 & 24.3 & & \\
\hline & Moderate & 146 & 17.4 & & \\
\hline & Severe & 488 & 58.2 & & \\
\hline
\end{tabular}

IQR interquartile range, ESS Epworth Sleepiness Scale, TST total sleep time, $A I$ arousal index, $D I$ desaturation index, $A H I$ apnea hypoapnea index, OSA obstructive sleep apnea 
Table 3 Comparison between patients with mild, moderate, and severe OSA

\begin{tabular}{|c|c|c|c|c|c|c|}
\hline & & \multicolumn{3}{|l|}{ OSA } & \multirow[t]{2}{*}{$p$} & \multirow[t]{2}{*}{ Sig } \\
\hline & & Mild, mean \pm SD & Moderate, mean $\pm S D$ & Severe, mean \pm SD & & \\
\hline \multicolumn{2}{|c|}{ Age (years) } & $53.75 \pm 12.21$ & $57.54 \pm 12.59$ & $55.19 \pm 5.44$ & $.256^{*}$ & NS \\
\hline \multicolumn{2}{|c|}{ Weight $(\mathrm{kg})^{\mathbf{a}}$} & $105.02 \pm 22.66$ & $102.57 \pm 23$ & $117.28 \pm 20.37$ & $.001^{*}$ & HS \\
\hline \multicolumn{2}{|c|}{ Height (cm) } & $169.9 \pm 12.27$ & $170.21 \pm 9.75$ & $173.14 \pm 90.87$ & $.722^{*}$ & NS \\
\hline \multicolumn{2}{|c|}{ BMI $\left(\mathrm{kg} / \mathrm{m}^{2}\right)^{\mathbf{a}}$} & $32.34 \pm 8.7$ & $31.76 \pm 7.87$ & $36.47 \pm 14.35$ & $.001^{*}$ & HS \\
\hline \multirow{2}{*}{\multicolumn{2}{|c|}{$N C(\mathrm{~cm})^{\mathbf{a}}$}} & $41.55 \pm 5.23$ & $40.5 \pm 4.93$ & $43.98 \pm 5.12$ & $.001^{*}$ & HS \\
\hline & & $N(\%)$ & $N(\%)$ & $N(\%)$ & & \\
\hline \multirow[t]{2}{*}{ Sex } & Male & $151(22.27 \%)$ & $110(16.22 \%)$ & $417(61.5 \%)$ & $.001^{* *}$ & HS \\
\hline & Female & 53 (33.13\%) & 36 (22.5\%) & 71 (44.38\%) & & \\
\hline
\end{tabular}

$B M I$ body mass index, $N C$ neck circumference

*ANOVA

${ }^{*}$ Chi-square test

${ }^{a}$ Mild vs. moderate (NS), mild vs. severe (HS), and moderate vs. severe (HS)

were those meeting the diagnostic criteria of OSA according to the Third Edition of the International Classification of Sleep Disorders and then categorized into mild (AHI 5-15), moderate (AHI 15-30), and severe $($ AHI $>30)$ [18]. Patients less than 18 years old and patients who underwent polysomnography for less than 4$\mathrm{h}$ duration were excluded.

\section{Study variables}

The primary objective was to determine the percentage of OSA in a large clinical sample. Secondly, we wanted to investigate the effect of age, gender, BMI, and $\mathrm{NC}$ on the severity of the AHI. We also explored the correlation between each of the age, BMI, NC with ESS, AHI, and other sleep parameters [average oxygen saturation $\left(\mathrm{SpO}_{2}\right)$, desaturation index (DI), arousal index (AI), and total sleep time (TST)] and compared sleep-related differences between men and women.

\section{Statistical analysis}

Kolmogorov-Smirnov's test was used to evaluate the normal distribution of continuous data. All results are presented as mean and SD values or as median and interquartile range according to the distribution of data. Categorical results are presented as numbers of cases and percentages. For univariate analysis, continuous variables were compared between 2 groups using the Student $t$ test or Mann-Whitney $U$ test depending on the distribution of data. ANOVA and Kruskal-Wallis tests were used to compare numerical variables between 3 groups according to data distribution with post hoc test for pair-wise comparisons. Categorical variables were compared using the chi-square test. Pearson's or Spearman correlation coefficients were used to assess the correlation between variables. Multivariate linear regression analysis was performed for finding the predictors of AHI. The $p$ value was considered significant as the following: $p>0.05$, not significant (NS); $p<0.05$, significant

Table 4 Comparison between patients with mild, moderate and severe OSA

\begin{tabular}{|c|c|c|c|c|c|c|c|c|}
\hline & \multicolumn{6}{|l|}{ OSA } & \multirow[t]{3}{*}{$p$} & \multirow[t]{3}{*}{ Sig } \\
\hline & \multicolumn{2}{|l|}{ Mild } & \multicolumn{2}{|l|}{ Moderate } & \multicolumn{2}{|l|}{ Severe } & & \\
\hline & Mean \pm SD & Med (IQR) & Mean \pm SD & Med (IQR) & Mean \pm SD & Med (IQR) & & \\
\hline$\overline{\mathrm{ESS}^{\mathrm{A}}}$ & $8.15 \pm 6$ & $7(4-12)$ & $9.01 \pm 5.44$ & $8(6-13)$ & $11.64 \pm 6.52$ & $12(7-16)$ & $.001^{*}$ & HS \\
\hline TST & $293.74 \pm 96.1$ & $290.7(241-352)$ & $294.42 \pm 90.87$ & $300.5(245-362.5)$ & $306.8 \pm 88.86$ & $314(250-369.5)$ & $.139^{* *}$ & NS \\
\hline $\mathrm{Al}^{\mathrm{A}}$. & $18.98 \pm 14.99$ & $16(10.1-22.8)$ & $21.8 \pm 14.35$ & $18.2(11.1-29.3)$ & $46.8 \pm 24.61$ & $45.65(25.4-65.5)$ & $.001^{* *}$ & HS \\
\hline $\mathrm{SpO}_{2}{ }^{\mathrm{A}}$ & $94.13 \pm 3.96$ & 95 (93-96) & $93.36 \pm 5.12$ & 94 (93-96) & $89.86 \pm 8.05$ & $92(88.5-94)$ & $.001^{*}$ & HS \\
\hline$\left.\mathrm{Dl}\right|^{\mathrm{B}}$ & $24.16 \pm 39.07$ & $14.4(7.3-25.3)$ & $34.38 \pm 29.47$ & $26(16.6-39.8)$ & $75.7 \pm 36.93$ & 75.5 (56.6-93.5) & $.001^{* *}$ & HS \\
\hline
\end{tabular}

IQR interquartile range, ESS Epworth Sleepiness Scale, $A$ I arousal index, $D /$ desaturation index *ANOVA

${ }^{*}$ Kruskal-Wallis test

${ }^{A}$ Mild vs. moderate (NS), mild vs. severe (HS), and moderate vs. severe (HS), by post hoc test

${ }^{B}$ Mild vs. moderate (S), mild vs. severe (HS), and moderate vs. severe (HS), by post hoc test 
Table 5 Correlation between each of age, BMI, and the NC with ESS, AHI, and sleep data

\begin{tabular}{|c|c|c|c|c|c|c|c|}
\hline & & $\mathrm{AHI}$ & ESS & TST & Al & $\mathrm{SpO}_{2}$ & DI \\
\hline \multirow[t]{3}{*}{ BMI $\left(\mathrm{kg} / \mathrm{m}^{2}\right)^{\mathrm{a}}$} & $R$ & .167 & .211 & -.147 & .187 & -.354 & .472 \\
\hline & $p$ & .0001 & .0001 & .0001 & .0001 & .0001 & .0001 \\
\hline & Sig & $\mathrm{HS}$ & $\mathrm{HS}$ & $\mathrm{HS}$ & $\mathrm{HS}$ & $\mathrm{HS}$ & HS \\
\hline \multirow[t]{3}{*}{$\mathrm{NC}(\mathrm{cm})^{\mathrm{a}}$} & $R$ & .267 & .133 & -.045 & .250 & -.284 & .338 \\
\hline & $p$ & .0001 & .001 & .236 & .0001 & .0001 & .0001 \\
\hline & Sig & $\mathrm{HS}$ & $\mathrm{HS}$ & NS & $\mathrm{HS}$ & $\mathrm{HS}$ & HS \\
\hline \multirow[t]{3}{*}{ Age (years) ${ }^{a}$} & $R$ & -.045 & .000 & -.130 & -.143 & -.017 & -.089 \\
\hline & $p$ & .194 & .997 & .0001 & .0001 & .626 & .012 \\
\hline & Sig & NS & NS & $\mathrm{HS}$ & $\mathrm{HS}$ & NS & $S$ \\
\hline
\end{tabular}

$B M I$ body mass index, NC neck circumference, $A H I$ apnea hypoapnea index, ESS Epworth Sleepiness Scale, TST total sleep time, $A$ l arousal index, DI desaturation index

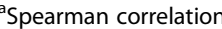

$(\mathrm{S})$; and $p<0.01$, highly significant (HS). All statistical procedures were carried out using SPSS version 20 for Windows (SPSS Inc., Chicago, IL, USA).

\section{Results}

\section{Patients}

The diagnosis of OSA was established in $838(83 \%)$ of the 1012 patients referred to our center for polysomnography evaluation. Among patients with OSA, 678 (81\%) were males and $160(19 \%)$ were females. Patients with mild OSA were 204 (24.3\%), and those with moderate OSA were $146(17.4 \%)$ while 488 (58.2\%) of the patients had severe OSA. Their characteristics are summarized in Table 1, and their sleep data are described in Table 2.

\section{Differences between mild, moderate, and severe OSA}

We found a highly significant difference between patients with mild, moderate, and severe OSA as regards the BMI, NC, ESS, AI, $\mathrm{SpO}_{2}$, and the DI $(p=0.001)$. These differences are shown in Table 3 and 4 . The increase in $\mathrm{BMI}$ and $\mathrm{NC}$ was highly associated with severe AHI and reduced $\mathrm{SpO}_{2}(p=0.0001)$. No significant association was found between the age and the AHI ( $p=$ 0.194). The correlations that were found between each of the age, BMI, NC with AHI, ESS, TST, $\mathrm{AI}, \mathrm{SpO}_{2}$, and the DI are described in Table 5. The linear regression analysis of the factors affecting the severity of OSA revealed that the BMI and the $\mathrm{NC}$ were the two risk factors that independently aggravated the severity of the AHI in our cohort (Table 6).

\section{Differences between males and females}

Comparison between the two sexes revealed that females were older than males $(58.87 \pm 10.25$ versus $54.39 \pm$ 22.96, $p=0.001$ ) and that the BMI was almost equal between both sexes $(34.18 \pm 13.53$ versus $36.73 \pm 23.25, p=$ 0.07 ), but the NC was significantly higher in men $(43.56 \pm 5.3$ versus $39.34 \pm 4.41, p=0.001)$. Hypertension coexisted in $41 \%(n=344)$ patients; $80 \%(n=277)$ of these patients were men and 20\% $(n=67)$ were women.

\section{Sleep parameters in men and women}

Sleep parameters were similar between males and females such as the TST $(302.46 \pm 90.5$ versus $297.59 \pm$ 93.97, $p=0.270)$, the $\mathrm{SpO}_{2}(91.85 \pm 6.47$ versus $90.11 \pm$ $9.01, p=0.416)$, and the DI $(54.36 \pm 39.48$ versus $62.79 \pm$ 56.47, $p=0.423)$. The AI was markedly high in men $(37.92 \pm 24.81$ versus $26.5 \pm 22.85, p=0.001)$. AHI was significantly increased in men compared to women $(47.97 \pm 31.22$ versus $37.95 \pm 31.72, p=0.001)$, and severe OSA was commonly diagnosed in men than in women $(p=0.001)$ as seen in Fig. 1 . The above sex differences are illustrated in Table 7.

\section{Discussion}

Obstructive sleep apnea is a common disorder leading to excessive daytime sleepiness and reduction in healthrelated quality of life that is usually associated with major cardiovascular complications [19]. It is generally accepted that the disorder is more common in men than in women [20], and many studies have outlined the sexrelated differences as well as the clinical and sleep characteristics of patients diagnosed with OSA in different populations [21-23].

The present study describes some of the demographics and clinical and sleep characteristics that were found in a large cohort of Egyptian patients diagnosed with OSA. Our objective was to identify the percentage of OSA among a large sample of Egyptian men and women referred to a sleep center for symptoms related to OSA; to evaluate the influence of age, gender, obesity, and $\mathrm{NC}$ on

Table 6 Linear regression analysis to determine the factors affecting the severity of OSA

\begin{tabular}{|c|c|c|c|c|c|}
\hline \multirow[b]{2}{*}{ Age (years) } & \multirow{2}{*}{$\begin{array}{l}\text { Regression coefficients } \\
-.015\end{array}$} & \multirow{2}{*}{$\begin{array}{l}p \\
.767\end{array}$} & \multirow{2}{*}{$\begin{array}{l}\text { Sig. } \\
\text { NS }\end{array}$} & \multicolumn{2}{|c|}{$95 \% \mathrm{Cl}$ for regression coefficients } \\
\hline & & & & -.115 & .085 \\
\hline Gender & -4.920 & .134 & NS & -11.367 & 1.526 \\
\hline BMI $\left(\mathrm{kg} / \mathrm{m}^{2}\right)$ & .213 & .002 & HS & .077 & .349 \\
\hline $\mathrm{NC}(\mathrm{cm})$ & 1.506 & .0001 & HS & 1.023 & 1.989 \\
\hline
\end{tabular}

OSA obstructive sleep apnea, BMI body mass index, NC neck circumference 


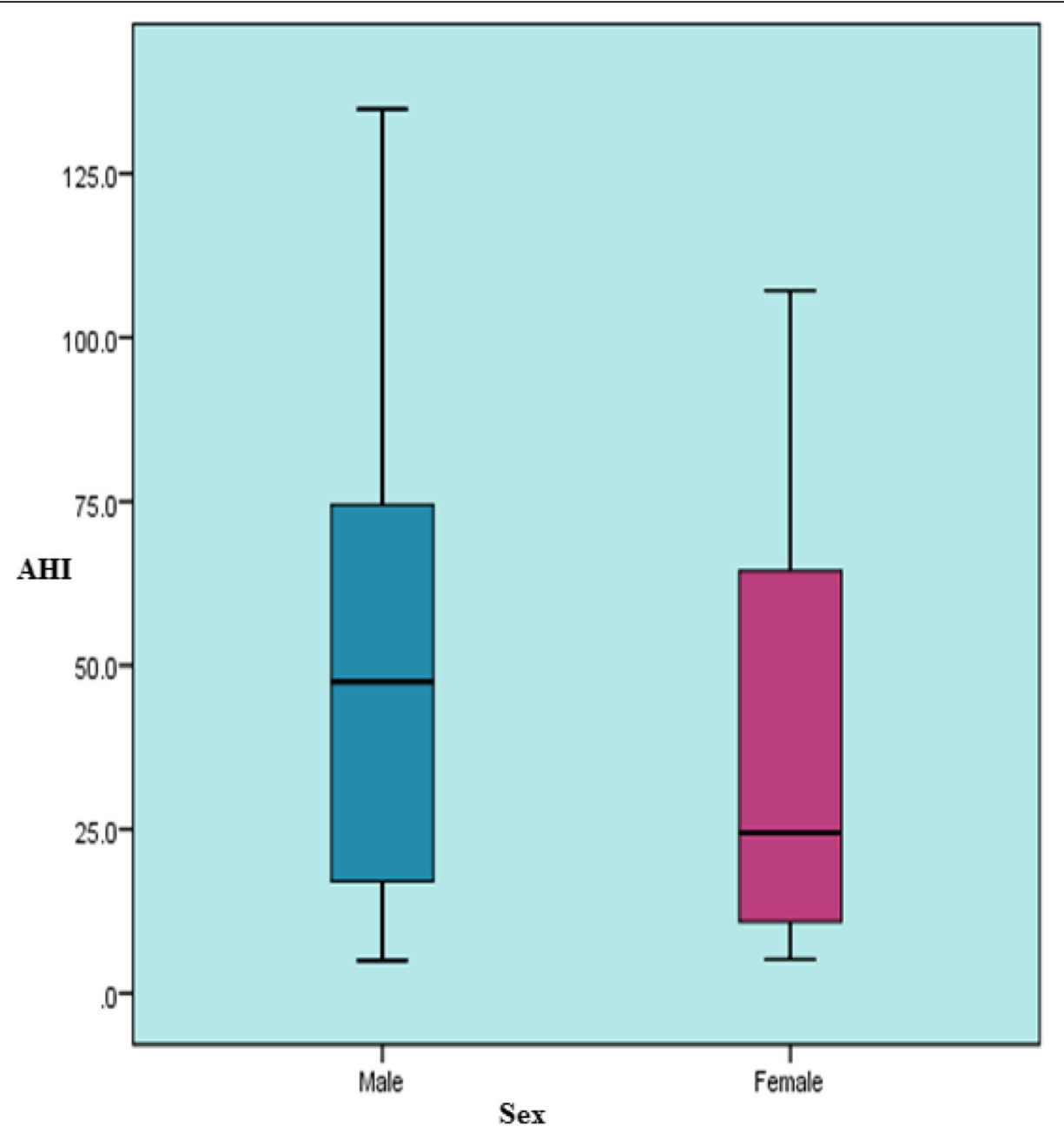

Fig. 1 Comparison of AHI severity between Egyptian men and women

the severity of their disease; and to recognize eventual differences between them.

In this work, $83 \%$ of the patients referred to our center were diagnosed with OSA, which is consistent with what was previously reported in different parts of Egypt. In the delta region, a study which included 50 patients found that $80 \%$ of them had OSA [24]. Also, in another work in the same region, an equal figure was found in a sample of 400 patients [25]. Authors from Alexandria evaluated 32 patients with tachyarrythmias by a level III sleep study and diagnosed 84\% with OSA [26]. A slightly higher rate was found in an earlier study conducted in Cairo on 230 patients showing that approximately $87 \%$ of the patients had OSA [27].

Our results differed from what was shown in a recent work that evaluated 170 patients in the south of Egypt in whom $59 \%$ were diagnosed with OSA agreeing to a recent work that evaluated 120 patients [28, 29]. Also, in a sample of 80 patients, OSA was diagnosed in $65 \%$ of them almost equal to another work that examined 145 patients referred for polysomnography [30, 31].

On a parallel note, obesity has long been considered to be a major risk factor for OSA, and the prevalence of OSA among obese individuals is approximately $40 \%$. Indeed, almost all men with class III obesity also have OSA [32, 33]. Practically, NC, waist circumference, BMI, and the size of the retroglossal space are regarded to have a major impact on the severity of OSA [34].

Not surprisingly, our results showed a positive significant correlation between BMI, NC with AHI, and other parameters of disease severity in agreement with a Turkish study that evaluated about 240 patients and found that severe AHI was associated with increased BMI [35]. In fact, the regression analysis of our results showed that $\mathrm{BMI}$ and NC were the only factors that independently affected the severity of OSA in our patients.

In the same clinical setting, age did not affect the severity of the disease in our studied patients. However, 
Table 7 Comparison between men and women diagnosed with OSA

\begin{tabular}{|c|c|c|c|c|c|c|}
\hline & \multicolumn{2}{|l|}{ Male } & \multicolumn{2}{|l|}{ Female } & \multirow[t]{2}{*}{$p$} & \multirow[t]{2}{*}{ Sig } \\
\hline & Mean \pm SD & Med (IQR) & Mean \pm SD & Med (IQR) & & \\
\hline Age (years) & $54.39 \pm 22.96$ & $54(44-63)$ & $58.87 \pm 10.25$ & $60(52-65.5)$ & $.001^{\mathrm{a}}$ & HS \\
\hline Weight (kg) & $113.69 \pm 46.99$ & $110(95-126)$ & $103.97 \pm 24$ & $101(86-119)$ & $.012^{\mathrm{a}}$ & S \\
\hline Height (cm) & $175.18 \pm 59.71$ & $174(168-178)$ & $157.94 \pm 13.44$ & $160(155-163)$ & $.001^{\mathrm{a}}$ & HS \\
\hline BMI $\left(\mathrm{kg} / \mathrm{m}^{2}\right)$ & $34.18 \pm 13.53$ & $32(28.3-37.7)$ & $36.73 \pm 23.25$ & $34.0(29.08-40.6)$ & $.07^{\mathrm{a}}$ & NS \\
\hline $\mathrm{NC}(\mathrm{cm})$ & $43.56 \pm 5.3$ & $43(41-46)$ & $39.34 \pm 4.41$ & $39(36-42)$ & $.001^{\mathrm{a}}$ & HS \\
\hline $\mathrm{AHI}$ & $47.97 \pm 31.22$ & $47.5(17.1-74.5)$ & $37.95 \pm 31.72$ & $24.45(10.9-64.4)$ & $.001^{\mathrm{b}}$ & HS \\
\hline ESS & $10.23 \pm 6.48$ & $9(5-15)$ & $10.82 \pm 6.11$ & $10(6-15)$ & $.304^{\mathrm{a}}$ & NS \\
\hline TST & $302.46 \pm 90.5$ & $314(246.5-368)$ & $297.59 \pm 93.97$ & $294.75(240-353.75)$ & $.270^{\mathrm{b}}$ & NS \\
\hline $\mathrm{Al}$ & $37.92 \pm 24.81$ & $31.07(17.5-58)$ & $26.5 \pm 22.85$ & $19.9(10.7-38.3)$ & $.001^{\mathrm{b}}$ & HS \\
\hline $\mathrm{SpO}_{2}$ & $91.85 \pm 6.47$ & 94 (90-95) & $90.11 \pm 9.01$ & $93(90-95)$ & $.416^{\mathrm{b}}$ & NS \\
\hline \multirow[t]{2}{*}{$\mathrm{Dl}$} & $54.36 \pm 39.48$ & $52.3(18.6-82.5)$ & $62.79 \pm 56.47$ & $47.8(19.4-88.3)$ & $.423^{\mathrm{b}}$ & NS \\
\hline & $N(\%)$ & & $N(\%)$ & & & \\
\hline \multirow[t]{3}{*}{ OSA } & Mild & $151(22.3 \%)$ & $53(33.1 \%)$ & & $.001^{c}$ & HS \\
\hline & Moderate & $110(16.2 \%)$ & $36(22.5 \%)$ & & & \\
\hline & Severe & 417 (61.5\%) & 71 (44.4\%) & & & \\
\hline
\end{tabular}

$I Q R$ interquartile range, $B M I$ body mass index, NC neck circumference, $A H I$ apnea hypoapnea index, OSA obstructive sleep apnea, ESS Epworth Sleepiness Scale, TST total sleep time, $A$ l arousal index, DI desaturation index

${ }^{\text {a }}$ Student $t$ test

${ }^{\mathrm{b}}$ Mann-Whitney test

${ }^{c}$ Chi-square test

age has been described to be a risk factor for the occurrence of OSA in the general population [36]. Also, the AHI was significantly associated with age [37]. It reported as well that OSA is predominantly a disease of middle-aged men $[2,20]$ whereas age higher than 60 years was considered the only risk factor for OSA in females [38] probably due to hormonal influences [39].

Additionally, in our cohort, OSA was more common in men (Fig. 1) which is concordant to what was classically published in various studies [23, 27, 31, 40-43]. Our study also revealed that severe OSA is highly diagnosed in men which is similar to the reports from different populations $[22,23,35,43]$ despite the fact that in our cohort, BMI was almost similar between men and women in contrast to what was published elsewhere [22, $31,40,44]$.

This discrepancy in the gender-related incidence of OSA is not entirely clear since women and men were described to have common symptoms such as snoring, witnessed apneas, and daytime sleepiness [45]. This sex-related difference has been attributed however to factors such as body fat distribution because men tend to have an upper body fat deposition in contrast to women. Increased fat tissue deposition in the pharyngeal region and reduced operating lung volumes in obesity act together to reduce the upper airway caliber, modify airway configuration, and increase their repetitive collapsibility [46].
Noteworthy, strong evidence linked OSA with HTN $[15,47,48]$, and interestingly, CPAP treatment demonstrated quite a large decrease in blood pressure values in patients with OSA [49]. Therefore, an important finding in our study is that $41 \%$ of the patients had associated HTN which is equivalent to European data [15]. Also, a work conducted in the south of Egypt observed that 45\% of the patients diagnosed with OSA had associated HTN [28]. Recently, authors from Cairo also showed that HTN existed in almost $50 \%$ of their patients with OSA [29]. These findings still require further investigations as two other Egyptian studies noticed a higher prevalence of coexistent OSA and HTN affecting $68 \%$ and $77 \%$ of their patients, respectively $[25,50]$.

In conclusion, our study assessed the frequency and risk factors of OSA in a large clinical cohort of Egyptian patients. We also confirmed that OSA is the sleep disorder mostly encountered around sleep centers in Egypt. Additionally, BMI and $\mathrm{NC}$ were the two risk factors that independently aggravated the severity of the $\mathrm{AHI}$ in our cohort.

Nevertheless, the present findings should be interpreted taking into consideration some limitations of the study. First, females were under-represented probably due to their traditional social role within the family leading to neglected or under-reported symptoms. Another explanation is that physicians may hesitate in referring women for sleep studies describing their main sleep 
complaint to be due to insomnia or depression. Also, we did not assess the waist to hip ratio which is considered a better measure of fat distribution for males and females diagnosed with OSA [51, 52]. Further, our work is retrospective, our clinic population is not representative of the community, and the results cannot be extrapolated on the general population.

Finally, fellow colleagues in Egypt particularly cardiologists and primary care physicians should be aware of the serious effects and complications of OSA (e.g., resistant HTN). Physicians should also orient women for sleep studies when they are presented with symptoms related to OSA.

The use of sleep questionnaires such as the ESS might be helpful as an initial screening tool for OSA. Further multicenter studies including a large number of patients are needed to confirm the extent of OSA, CPAP effects, and the related cardiovascular consequences among Egyptian patients.

\section{Abbreviations \\ AHI: Apnea hypoapnea index; Al: Arousal index; BMl: Body mass index; CPAP: Continuous positive airway pressure; CV: Cardiovascular; DI: Desaturation index; ESS: Epworth Sleepiness Scale; HTN: Hypertension; NC: Neck circumference; OSA: Obstructive sleep apnea; $\mathrm{SpO}_{2}$ : Peripheral capillary oxygen saturation; TST: Total sleep time}

\section{Acknowledgements}

None

\section{Authors' contributions}

AG: literature search, manuscript preparation, writing, review, and editing. SL: manuscript review. All authors have read and approved the final manuscript.

\section{Funding}

None

\section{Availability of data and materials}

All data generated or analyzed during this study are included in this published article.

\section{Ethics approval and consent to participate}

This study was conducted in accordance with the International Committee of Harmonization Guidelines for Good Clinical Practice with applicable local regulations and ethical principles laid down in the Declaration of Helsinki

\section{Consent for publication}

Not applicable

\section{Competing interests}

The authors declare that they have no competing interests.

Received: 16 May 2020 Accepted: 21 September 2020

Published online: 01 October 2020

\section{References}

1. Lévy P, Kohler M, McNicholas WT, Barbé F, McEvoy RD, Somers VK et al (2015) Obstructive sleep apnoea syndrome. Nat Rev Dis Primers 1:15015

2. Deng X, Gu W, Li Y, Liu M, Li Y, Gao X. Age-group-specific associations between the severity of obstructive sleep apnea and relevant risk factors in male and female patients. PLoS One [Internet]. 201411 [cited 2019 Jul 17]; 9(9). Available from: https://www.ncbi.nlm.nih.gov/pmc/articles/ PMC4161416/
3. Javaheri S, Barbe F, Campos-Rodriguez F, Dempsey JA, Khayat R, Javaheri S et al (2017) Sleep apnea: types, mechanisms, and clinical cardiovascular consequences. J Am Coll Cardiol 69(7):841-858

4. Peppard PE, Young T, Barnet JH, Palta M, Hagen EW, Hla KM (2013) Increased prevalence of sleep-disordered breathing in adults. Am J Epidemiol 177(9):1006-1014

5. Abolfotouh MA, Sallam SA, Mohammed MS, Loutfy AA, Hasab AA (2011) Prevalence of elevated blood pressure and association with obesity in Egyptian school adolescents. Int J Hypertens 2011:952537

6. Ibrahim MM, Elamragy AA, Girgis H, Nour MA (2011) Cut off values of waist circumference and associated cardiovascular risk in Egyptians. BMC Cardiovasc Disord 11:53

7. Sliem HA, Ahmed S, Nemr N, El-Sherif I (2012 Jan) Metabolic syndrome in the Middle East. Indian J Endocrinol Metab 16(1):67-71

8. Appleton SL, Gill TK, Lang CJ, Taylor AW, McEvoy RD, Stocks NP et al (2018) Prevalence and comorbidity of sleep conditions in Australian adults: 2016 sleep Health Foundation national survey. Sleep Health 4(1):13-19

9. Tveit RL, Lehmann S, Bjorvatn B (2018) Prevalence of several somatic diseases depends on the presence and severity of obstructive sleep apnea. PLoS One 13(2):e0192671

10. Bonsignore MR, Baiamonte P, Mazzuca E, Castrogiovanni A, Marrone O (2019) Obstructive sleep apnea and comorbidities: a dangerous liaison. Multidiscip Respir Med 14:8

11. Jennum P, Tønnesen P, Ibsen R, Kjellberg J (2015) All-cause mortality from obstructive sleep apnea in male and female patients with and without continuous positive airway pressure treatment: a registry study with 10 years of follow-up. Nat Sci Sleep 7:43-50

12. Mokhlesi B, Ham SA, Gozal D (2016 Apr) The effect of sex and age on the comorbidity burden of OSA: an observational analysis from a large nationwide US health claims database. Eur Respir J 47(4):1162-1169

13. Drager LF, Polotsky WY, O'Donnell CP, Cravo SL, Lorenzi-Filho G, Machado BH (2015 Oct) Translational approaches to understanding metabolic dysfunction and cardiovascular consequences of obstructive sleep apnea. Am J Physiol Heart Circ Physiol 309(7):H1101-H1111

14. Baltzis D, Bakker JP, Patel SR, Veves A (2016) Obstructive sleep apnea and vascular diseases. Compr Physiol 6(3):1519-1528

15. Tkacova R, McNicholas WT, Javorsky M, Fietze I, Sliwinski P, Parati G et al (2014) Nocturnal intermittent hypoxia predicts prevalent hypertension in the European sleep Apnoea database cohort study. Eur Respir J 44(4):931-941

16. El Mawardy R, Okba A (2017) Antihypertensive treatment and blood pressure control in patients with hypertension in daily clinical practice: a cross-sectional, multicenter, observational study in Egypt. Curr Med Res Opin 33(1):39-45

17. Berry RB, Budhiraja R, Gottlieb DJ, Gozal D, Iber C, Kapur VK et al (2012) Rules for scoring respiratory events in sleep: update of the 2007 AASM manual for the scoring of sleep and associated events. Deliberations of the sleep apnea definitions task force of the American Academy of sleep medicine. J Clin Sleep Med 8(5):597-619

18. Sateia MJ (2014) International classification of sleep disorders-third edition: highlights and modifications. Chest. 146(5):1387-1394

19. Peppard PE, Young T, Palta M, Skatrud J (2000) Prospective study of the association between sleep-disordered breathing and hypertension. N Engl J Med 342(19):1378-1384

20. Young T, Palta M, Dempsey J, Skatrud J, Weber S, Badr S (1993) The occurrence of sleep-disordered breathing among middle-aged adults. N Engl J Med 328(17):1230-1235

21. Al-Abri M, Al-Hashmi K, Jaju D, Al-Rawas O, Al-Riyami B, Hassan M (2011) Gender difference in relationship of apnoea/hypopnoea index with body mass index and age in the Omani population. Sultan Qaboos Univ Med J 11(3):363-368

22. Alotair H, Bahammam A (2008) Gender differences in Saudi patients with obstructive sleep apnea. Sleep Breath 12(4):323-329

23. Vagiakis E, Kapsimalis F, Lagogianni I, Perraki H, Minaritzoglou A, Alexandropoulou K et al (2006) Gender differences on polysomnographic findings in Greek subjects with obstructive sleep apnea syndrome. Sleep Med 7(5):424-430

24. Suliman L, Shalabi N, Elmorsy A, Moawed M (2017) Value of STOP-BANG and Berlin questionnaires in the diagnosis and severity prediction of obstructive sleep apnea hypopnea syndrome. Egypt J Bronchol 11:367

25. Yousif M, El-Helbawy R (2013) A six-year sleep lab experience in an Egyptian University hospital. Egypt J Chest Dis Tuberculosis. 62(4):717-722 
26. Mourad S, Abdel Wahab N, Fayed A, Kassem A, Alsayed H (2017) Occurrence of sleep related breathing disorders in Egyptian patients with tachyarrhythmia without heart failure. Egypt J Chest Dis Tubercul 66(1):127-136

27. El-Sayed IH (2012) Comparison of four sleep questionnaires for screening obstructive sleep apnea. Egypt J Chest Dis Tubercul. 61(4):433-441

28. Esmaeel H, Mohammadien H, Saleh A-E, Mohamed F (2019) Prepolysomnography evaluation can predict obstructive sleep apnea and is correlated to its severity. Egypt J Bronchol. 13:556

29. Galal M, Kamal E (2019) Clinical features and predictors of obesity hypoventilation syndrome among patients with obstructive sleep apnea. Egypt J Chest Dis Tuberculosis 68(2):209

30. Ali E, Mohamad A (2017) Evaluation of the efficiency of anthropometric parameters and submental ultrasonographic indices as predictors for screening of obstructive sleep apnea and its severity. Egypt J Bronchol. 11:355

31. Assal HH, Kamal E (2016) Gender differences in polysomnographic findings in Egyptian patients with obstructive sleep apnea syndrome. Egyptian J Chest Dis Tubercul. 65(3):649-654

32. Resta O, Foschino-Barbaro MP, Legari G, Talamo S, Bonfitto P, Palumbo A et al (2001) Sleep-related breathing disorders, loud snoring and excessive daytime sleepiness in obese subjects. Int J Obes Relat Metab Disord 25(5): 669-675

33. Valencia-Flores M, Orea A, Castaño VA, Resendiz M, Rosales M, Rebollar V et al (2000) Prevalence of sleep apnea and electrocardiographic disturbances in morbidly obese patients. Obes Res 8(3):262-269

34. McClean KM, Kee F, Young IS, Elborn JS (2008) Obesity and the lung: 1. Epidemiol Thorax 63(7):649-654

35. Bozkurt MK, Öy A, Aydın D, Bilen SH, Ertürk iÖ, Saydam L et al Gender differences in polysomnographic findings in Turkish patients with obstructive sleep apnea syndrome. Eur Arch Otorhinolaryngol 265(7):821-824

36. Bixler EO, Vgontzas AN, Ten Have T, Tyson K, Kales A (1998) Effects of age on sleep apnea in men: I. prevalence and severity. Am J Respir Crit Care Med 157(1):144-148

37. Tishler PV, Larkin EK, Schluchter MD, Redline S (2003) Incidence of sleepdisordered breathing in an urban adult population: the relative importance of risk factors in the development of sleep-disordered breathing. JAMA. 289(17):2230-2237

38. Sin DD, Fitzgerald F, Parker JD, Newton G, Floras JS, Bradley TD (1999) Risk factors for central and obstructive sleep apnea in 450 men and women with congestive heart failure. Am J Respir Crit Care Med 160(4):1101-1106

39. Bixler EO, Vgontzas AN, Lin HM, Ten Have T, Rein J, Vela-Bueno A et al (2001) Prevalence of sleep-disordered breathing in women: effects of gender. Am J Respir Crit Care Med 163(3 Pt 1):608-613

40. O'Connor C, Thornley KS, Hanly PJ (2000) Gender differences in the polysomnographic features of obstructive sleep apnea. Am J Respir Crit Care Med 161(5):1465-1472

41. Quintana-Gallego E, Carmona-Bernal C, Capote F, Sánchez-Armengol A, Botebol-Benhamou G, Polo-Padillo J et al (2004) Gender differences in obstructive sleep apnea syndrome: a clinical study of 1166 patients. Respir Med 98(10):984-989

42. Yuceege M, Firat H, Ardic S, Demir A (2014) Gender difference in apnea and hypopnea component in obstructive sleep apnea. J Turkish Sleep Med 1: $16-21$

43. Yukawa K, Inoue Y, Yagyu H, Hasegawa T, Komada Y, Namba K et al (2009) Gender differences in the clinical characteristics among Japanese patients with obstructive sleep apnea syndrome. Chest. 135(2):337-343

44. Gabbay IE, Lavie P (2012) Age- and gender-related characteristics of obstructive sleep apnea. Sleep Breath 16(2):453-460

45. Lin CM, Davidson TM, Ancoli-Israel S (2008) Gender differences in obstructive sleep apnea and treatment implications. Sleep Med Rev 12(6): 481-496

46. Sériès F (2002) Upper airway muscles awake and asleep. Sleep Med Rev 6(3):229-242

47. Fuchs FD, Fuchs SC, Martinez D (2017) Obstructive sleep apnea—hypertension link: almost there? J Thorac Dis 9(10):3537-3540

48. Marrone O, Bonsignore MR (2018) Blood-pressure variability in patients with obstructive sleep apnea: current perspectives. Nat Sci Sleep. 10:229-242

49. Sun Y, Huang Z-Y, Sun Q-R, Qiu L-P, Zhou T-T, Zhou G-H (2016) CPAP therapy reduces blood pressure for patients with obstructive sleep apnoea: an update meta-analysis of randomized clinical trials. Acta Cardiol 71(3): $275-280$
50. Sweed RA, Hassan S, ElWahab NHA, Aref SR, Mahmoud MI (2019) Comorbidities associated with obstructive sleep apnea: a retrospective Egyptian study on 244 patients. Sleep Breath 26

51. Lim Y-H, Choi J, Kim KR, Shin J, Hwang KG, Ryu S et al (2014) Sex-specific characteristics of anthropometry in patients with obstructive sleep apnea: neck circumference and waist-hip ratio. Ann Otol Rhinol Laryngol 123(7): 517-523

52. Seidell JC (2010) Waist circumference and waist/hip ratio in relation to allcause mortality, cancer and sleep apnea. Eur J Clin Nutr 64(1):35-41

\section{Publisher's Note}

Springer Nature remains neutral with regard to jurisdictional claims in published maps and institutional affiliations.

\section{Submit your manuscript to a SpringerOpen ${ }^{\circ}$ journal and benefit from:}

- Convenient online submission

- Rigorous peer review

- Open access: articles freely available online

- High visibility within the field

- Retaining the copyright to your article

Submit your next manuscript at $\boldsymbol{\nabla}$ springeropen.com 